\title{
Optimization of the Autoclave-Assisted Alkaline Delignification of Cocoa (Theobroma cacao) Pod Husks Using KOH to Maximize Reducing Sugars
}

Leygnima Yaya Ouattara, ${ }^{\mathrm{a}, *}$ Doudjo Soro, ${ }^{\mathrm{a}}$ Guy Didier Fanou, ${ }^{\mathrm{a}}$ Esaïe Kouadio Appiah Kouassi, ${ }^{a}$ Massé Bamba, ${ }^{a}$ Kouassi Benjamin Yao, ${ }^{a}$ Kopoin Adouby, ${ }^{a}$ Allali Patrick Drogui, ${ }^{b}$ and Dayal Rajeshwar Tyagi ${ }^{b}$

\begin{abstract}
Cocoa pod husks are a type of biomass that is still poorly explored. This work was carried out as part of the optimization of the delignification process for this residue with potassium hydroxide, to maximize the reducing sugars content. Screening for potentially influencing factors showed that the biomass to solvent ratio and the temperature had the greatest effect on the delignification process. Optimization of these factors using a composite central plan revealed that the quadratic model was the most suitable for predicting the rate of delignification. The predicted $\mathrm{R}^{2}$ (0.815) was in good agreement with the adjusted $R^{2}(0.906)$. The correlation coefficient $\left(R^{2}=0.945\right)$ between the predicted and experimental results confirmed the fit of the model. The optimal conditions were a biomass to solvent ratio of $9.14 \%$ and a temperature of $128{ }^{\circ} \mathrm{C}$, which resulted in a maximum degree of delignification of $93.9 \%$, with $80 \%$ of the solids recovered. This study found that the removal of extractables before the pretreatment considerably improved the delignification of cocoa pod husks and the production of reducing sugars, which increased from $3.15 \pm 0.006 \mathrm{mg} / \mathrm{mL}$ to $5.33 \pm 0.143 \mathrm{mg} / \mathrm{mL}$. Scanning electron microscopy and $\mathrm{X}$-ray diffraction confirmed physicochemical changes in the biomass after pretreatment.
\end{abstract}

DOI: 10.15376/biores.17.1.826-848

Keywords: Cocoa pod husk; Delignification; Potassium hydroxide; Optimization; Central composite design; Reducing sugars

Contact information: a: Laboratoire des Procédés Industriels de Synthèse, de l'Environnement et des Energies Nouvelles (LAPISEN), Unité Mixte de Recherche et d'Innovation en Sciences des Procédés Chimiques, Alimentaires Environnementaux et Énergétiques, Institut National Polytechnique Félix Houphouët-Boigny, Yamoussoukro, Côte d'Ivoire; b: Institut National de la Recherche Scientifique (INRS Eau Terre et Environnement), Université du Québec, 490 rue de la Couronne, Québec City, Canada;

*Corresponding author:leygnima.ouattara18@inphb.ci

\section{INTRODUCTION}

Due to growing concerns about the environment, climate change, and increasingly scarce natural resources, efforts have recently been made to produce chemicals and materials from renewable biomass (Lee et al. 2011). Lignocellulosic biomass, which is a renewable and abundant resource, can be envisioned as the only sustainable resource for the production of chemicals (Mansur et al. 2014). In this context, several studies have focused on the use of lignocellulosic residues as raw materials, thanks to their availability as organic residues and to the fact that they are not fully exploited in current agro-industrial production systems (Bensah and Mensah 2013; Sharma et al. 2013; Bensah and Mensah 
2018; Ghazanfar et al. 2018; Júnior et al. 2020).

The cocoa pod husk $(\mathrm{CPH})$ is a carbohydrate-rich lignocellulosic source (43.9\% to 45.2\%) (Samah et al. 2011). It is highly abundant and available in West African countries, e.g., Côte d'Ivoire, which produced 2.15 million tons of cocoa beans in 2019, or $42 \%$ of the total world production (ICCO 2019; Statista 2019). At the same time, the production of $\mathrm{CPH}$ is estimated at 6.450 million tons, which constitutes more than $75 \%$ of the dry weight of the whole fruit (Cruz et al. 2012; Campos-Vega et al. 2018).

This residue is available and abundant in Côte d'Ivoire. In addition, its valorization potential has been demonstrated (Ouattara et al. 2021). However, the carbohydrates contained in this lignocellulosic biomass are found in a network consolidated by lignin. Therefore, delignification is needed to modify this structure in order to access these carbohydrates (Arenas-Cárdenas et al. 2017). In this context, the use of appropriate delignification strategies is necessary and crucial in order to reduce the recalcitrant nature of this biomass (Dahunsi et al. 2019a). As such, delignification is a key step in the process of converting lignocellulosic biomass into valuable products. It aims to destructure the lignins and disrupt the crystal structure of the cellulose and hemicellulose to increase the amorphous portion in order to increase the accessibility of the biomass to enzymatic saccharification, or acid hydrolysis, to generate fermentable monosaccharides (Thamsee $e t$ al. 2019; Dąbkowska-Susfał 2020).

Thus, the optimization of the delignification conditions prior to the lignocellulosic biomass development process should be one of the most important steps in the development of an efficient and economical method (Jung et al. 2017). Consequently, several delignification strategies have been explored, e.g., physical, physico-chemical, chemical, biological, and combined delignification. However, the physicochemical and physical delignification processes are inefficient and biological delignification processes are expensive and can be time consuming. As such, chemical delignification processes are the most utilized type, and the alkaline delignification in particular has met with considerable success (Premkumari et al. 2019). Delignification using alkalis can efficiently and selectively remove lignins, thus increasing the digestibility of cellulose. In addition, they lead to less formation of inhibitory compounds and less solubilized hemicelluloses as well as being generally carried out at low temperatures (Jönsson and Martín 2016). The primary mechanisms of alkaline delignification include cell wall disruption, carbohydrate solubilization, and the removal of the inhibitors of cellulose accessibility, namely lignins (Júnior et al. 2020). Solvation and saponification are the first reactions (Ghazanfar et al. 2018).

Several studies have shown the effectiveness of alkaline delignification for the delignification of $\mathrm{CPH}$. Thus, acid and alkaline delignification were performed on this residue, using sulfuric acid $\left(\mathrm{H}_{2} \mathrm{SO}_{4}\right)$ and sodium hydroxide $(\mathrm{NaOH})$, in order to determine their effects on the increase in the potential of biogas production via anaerobic digestion (Ward-Doria et al. 2016). The alkali delignification showed the best reductions in lignins, reaching a maximum value of $43.8 \%$. In addition, studies by Dahunsi et al. (2019a,b) have produced biogas from the mono-fermentation of cocoa pods pretreated with sulfuric acid and alkaline hydrogen peroxide. The results of these studies further revealed that the use of low-cost mild alkali is more effective in solubilizing lignins and further improving biogas yield. However, the authors did not find any optimization studies that looked at the delignification of cocoa pod husk with potassium hydroxide $(\mathrm{KOH})$, which is an alkali that could potentially pretreat cocoa pod husks. Potassium hydroxide has a very strong reactivity to carbon nanofibers and carbon nanostructures as well as a great capacity for 
the deacetylation of biomass (Paixão et al. 2016). In addition, the resulting filtrate could be efficiently reused for further delignification and could also be used to produce potassium fertilizer (Xie et al. 2018). In this context, other biomasses have been pretreated using this alkali and evaluated to produce bioproducts. Thus, the delignification of sugarcane bagasse with potassium hydroxide has been performed in order to improve enzymatic hydrolysis (Paixão et al. 2016). A mild $\mathrm{KOH}$ and glycerol delignification was applied to four West African biomasses (bamboo, rubber, elephant grass, and Siam grass) (Bensah et al. 2019). In addition, a comparison of the $\mathrm{NaOH}$ and $\mathrm{KOH}$ delignification using rice straw has been made by some authors. They showed that at an equal hydrolytic enzymatic load, the $\mathrm{KOH}$ treatment led to a higher sugar content than the $\mathrm{NaOH}$ treatment (Ong et al. 2010).

Most studies on the pretreatment of lignocellulosic biomass have been less interested in the removal of extractables before delignification. However, He et al. (2008) showed that substrates lacking these substances after pretreatment were favorable in terms of the improvement of biodegradability and biogas production. This study focused primarily on the removal of these extractables before the delignification process, in order to dissolve waxes, fats, and other impurities. Subsequently, the factors likely to influence the pretreatment of this residue with potassium hydroxide were examined, followed by the optimization of the most influential factors using a central composite design (CCD) based on a response surface methodology (RSM). The optimal conditions from this study will be applied to produce reducing sugars by being used as inputs in the bioproducts production.

\section{EXPERIMENTAL}

\section{Vegetal Material}

The plant material exhibited in Fig. 1 consists primarily of cocoa pods husks from the cocoa harvest in the Soubré region (Southwest Ivory Coast).
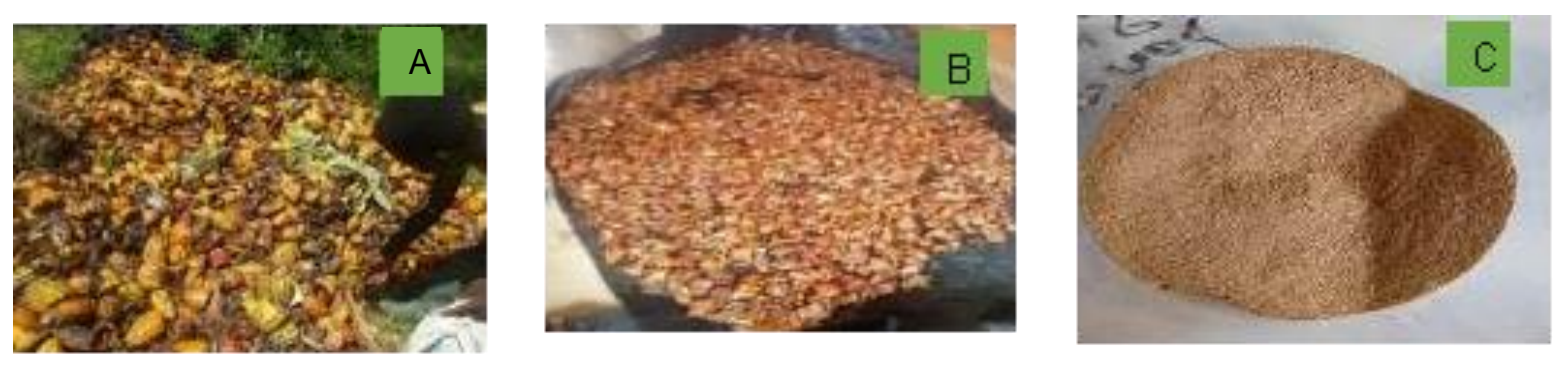

Fig. 1. Cocoa pod husk: Fresh (A); dry (B); and powder (C)

\section{Chemicals and Solvents}

The chemicals and solvents were of analytical grade.

\section{Methods}

\section{Harvesting the material}

The ripe cocoa pods husks were harvested from a plantation in the village of Balodougou (Soubré). This plantation is a high productivity cocoa plantation, in the region of Nawa (South-West, Ivory Coast) between latitudes $5^{\circ} 47^{\prime} 22.14348^{\prime \prime} \mathrm{N}$ and $5^{\circ} 50^{\prime} 1.1742^{\prime \prime} \mathrm{N}$ and longitudes $6^{\circ} 32^{\prime} 50.60112^{\prime \prime} \mathrm{W}$ and $6^{\circ} 35^{\prime} 38.16492^{\prime \prime} \mathrm{W}$. The selected fruits were sorted and then dry cleaned to remove impurities, e.g., dust. Each pod was cut 
into two parts to remove the pulpy seeds and mucilage. The cocoa pods husks were then washed thoroughly with water several times to remove the residual mucilage, then roughly chopped using a stainless-steel knife.

\section{Drying and grinding the material}

The fresh $\mathrm{CPH}$ were cut into small pieces, dried in the sun for $48 \mathrm{~h}$, and then further dried at a temperature of $60{ }^{\circ} \mathrm{C}$ in a hot air dryer (an electric hot air food dryer) for $24 \mathrm{~h}$. The cocoa pods husks were crushed into finer particles with a laboratory hammer mill ( $A R$ $108 B$ ) and then sieved through a screen fitted with a $250 \mu \mathrm{m}$ sieve. Then, the CPH particles were packed in polyethylene containers to prevent moisture uptake before being stored at room temperature for later analysis.

\section{Extractables and lignocellulosic content}

The extractables were removed according to the procedure outlined by Poursat (2015). The amount of lignins insoluble in sulfuric acid was determined via gravimetry following the laboratory analysis procedure (LAP) adopted by the National Renewable Energy Laboratory (NREL) (Sluiter et al. 2012). The holocellulose content was analyzed via by the chlorite method (Boudjema 2016). The cellulose was isolated from holocellulose after the solubilization of hemicelluloses in a dilute hydroxide solution (Bourahli 2018). The hemicellulose content was obtained by subtraction between the content of celluloses and that of holocelluloses.

\section{Determination of Total Phenolic Content (TPC)}

To verify the degradation of lignin in the delignified sample, the total phenolic compounds in the filtrate were estimated by the Folin-Ciocalteu method.

To $1 \mathrm{~mL}$ of the filtrate resulting from the optimized delignification $9.14 \%(\mathrm{w} / \mathrm{v}), 9$ $\mathrm{mL}$ of distilled water were added and then $30 \mu \mathrm{L}$ were taken and placed in a test tube. To this test sample, $2.5 \mathrm{~mL}$ of Folin-Ciocalteu reagent was added. After mixing, it was left to stand for $10 \mathrm{~min}$, and $2 \mathrm{~mL}$ of $\mathrm{Na}_{2} \mathrm{CO}_{3}$ solution $(7.5 \%$, w/v) was added for neutralization. The whole was heated for $15 \mathrm{~min}$ and then left to stand for $2 \mathrm{~h}$ at a temperature of $30{ }^{\circ} \mathrm{C}$. Finally, the absorption at $765 \mathrm{~nm}$ was measured with a UV-vis spectrophotometer.

\section{Estimation of reducing sugars}

The amount of reducing sugars released were estimated using the dinitrosalicylic acid (3,5-DNS) method outlined in Miller (1959) using a UV-visible spectrophotometer (UV/VIS Jasco V-530).

\section{Scanning electron microscopy (SEM) analysis}

The micrographic study of the CPH was carried out using a SH-4000 M (Hirox, Tokyo, Japan) scanning electron microscope at the following conditions: 15 to $20 \mathrm{~nm}$, a magnification of $30 \mathrm{x}$ to $60000 \mathrm{x}$, and an acceleration voltage of 5 to $30 \mathrm{kV}$ in 5 steps. In addition, energy-dispersive X-ray spectroscopy (EDS) was performed with a XFlash 6/30 detector (Brucker, Billerica, MA).

\section{$X$-ray diffraction and crystallinity}

X-ray diffraction allows an internal assessment of the cellulosic microstructure of a sample in terms of its crystal characteristics. The equipment was operated at a potential of $60 \mathrm{kV}$ and a current of $80 \mathrm{~mA}$ at a power of $3 \mathrm{~kW}$, and the samples were scanned over 
an angular range of $10^{\circ}$ to $90^{\circ}$ using a XRD diffractometer (EMMA (enhanced multimaterial analysis), IGBT, GBC Scientific Equipment, Braeside, Australia). The crystallinity index was calculated according to Eq. 1,

$$
\operatorname{CrI}=\frac{I_{002}-I_{a m}}{I_{002}}
$$

where $\mathrm{CrI}$ is the cellulose crystallinity index (\%), I002 is the intensity of the crystalline part of cellulose $\left(2 \theta=22.10^{\circ}\right.$ and $\left.22.32^{\circ}\right)$, and $I_{\mathrm{am}}$ is the intensity of the amorphous part of cellulose $\left(2 \theta\right.$ of between $18.30^{\circ}$ and $18.86^{\circ}$ ) (Segal et al. 1959).

\section{Optimization of the Thermochemical Pretreatment}

The pretreatment of the cocoa pod husks was carried out with $\mathrm{KOH}$, after removing the extractables in an alternating bath of ethanol and water.

\section{Factor screening plan}

Plackett and Burman screening experimental designs estimate the primary effects or 'weights' of $\mathrm{k}$ factors on a given property (response) to distinguish the truly influential factors. These designs use experimental orthogonal Hadamard matrices made up of low level (-1) and high level (+1) entries (Rais et al. 2011). The experiments number $(N)$ that composes these matrices is always a multiple of 4 . These matrices are used to separate the factors according to their influence on the response. Hadamard matrices allow the calculating of the effects of $k$ factors, with $k$ less than or equal to $N-1$. It is a fractional factorial design (Sivamani and Baskar 2014) based on a first order linear regression model as follows :

$y=b_{0}+\sum b_{i} x_{i}$

The interception coefficient $b_{0}$ is the main effect and is calculated as follows :

$b_{0}=\frac{\sum_{i=1}^{N} Y_{i}}{N}$

The effects $\left(b_{i}\right)$ of the factors were determined following Eq. 4, and was analyzed using NemrodW (2000 version, NemrodW, Peypin, France).

$b_{i}=\frac{\left(\sum Y^{+}-\sum Y^{-}\right)}{N}$

The symbols $\mathrm{Y}^{+}$and $\mathrm{Y}^{-}$represent responses of trials in which the independent factors are at high and low levels, respectively, and $\mathrm{N}$ is the number of trials. The positive coefficient increases the response while the response decreases for the negative coefficient. On the classical statistical significance tests (Student's t test), factors with a high coefficient value are considered significant whether they are positive or negative. Therefore, a Plackett and Burman type screening scheme was used to determine the influence of five factors, i.e., the alkali concentration $(\%)$, contact time $(h)$ at room temperature, biomass to solvent ratio $(\%)$, autoclaving time $(\mathrm{min})$, and reaction temperature $\left({ }^{\circ} \mathrm{C}\right)$.

\section{Delignification process}

The main factors involved in the delignification process and their domains of variation were chosen on the basis of previous studies (Nazir et al. 2016; Ghazanfar et al. 2018; Premkumari et al. 2019). A mass of cocoa pod husks was placed in a $250 \mathrm{~mL}$ flask, containing $100 \mathrm{~mL}$ of $\mathrm{KOH}$ with a concentration of between 1 and $5 \% \mathrm{w} / \mathrm{v}$ and according to the biomass to solvent ratio varying from 5 to $10 \% \mathrm{w} / \mathrm{v}$, given by the design of the experimental design. The mixture was subjected to room temperature for a period of between $4 \mathrm{~h}$ and $8 \mathrm{~h}$, then at $30^{\circ} \mathrm{C}$ in a water bath or at $130{ }^{\circ} \mathrm{C}$ in an autoclave (Digital 
vertical autoclave LX-C, HEFEI Huatai medical equipment co. LTD), for a time ranging from 15 to $60 \mathrm{~min}$. Tables 1 and 2 exhibits the experimental field and the experiment matrix, respectively.

Table 1. Experimental Area of the Screening Plan

\begin{tabular}{|c|c|c|}
\hline Variables & Level $(-1)$ & Level $(+1)$ \\
\hline Concentration $(\mathrm{KOH})(\%)(\mathrm{A})$ & 1 & 5 \\
\hline Biomass to solvent ratio (\%) (B) & 5 & 10 \\
\hline Contact time (h) (C) & 4 & 7 \\
\hline Heating time (min) (D) & 15 & 60 \\
\hline Temperature (C) (A) & 30 & 130 \\
\hline
\end{tabular}

Table 2. Experimental Matrix of the Screening Plan

\begin{tabular}{|c|c|c|c|c|c|}
\hline Assay & $\begin{array}{c}\mathrm{KOH} \\
\text { Concentration (\%) }\end{array}$ & $\begin{array}{c}\text { Biomass to Solvent } \\
\text { Ratio }(\%)\end{array}$ & $\begin{array}{c}\text { Contact } \\
\text { Time }(\mathrm{h})\end{array}$ & $\begin{array}{c}\text { Heating Time } \\
(\mathrm{min})\end{array}$ & $\begin{array}{c}\text { Temperature } \\
\left({ }^{\circ} \mathrm{C}\right)\end{array}$ \\
\hline 1 & 1 & 1 & -1 & -1 & -1 \\
\hline 2 & -1 & 1 & 1 & 1 & -1 \\
\hline 3 & -1 & -1 & 1 & -1 & 1 \\
\hline 4 & 1 & -1 & 1 & 1 & -1 \\
\hline 5 & -1 & 1 & -1 & 1 & 1 \\
\hline 6 & 1 & -1 & -1 & 1 & 1 \\
\hline 7 & 1 & 1 & 1 & -1 & 1 \\
\hline 8 & -1 & -1 & -1 & -1 & -1 \\
\hline
\end{tabular}

After this operation, the delignified solid substrate was separated from the hydrolysate obtained by filtration through Whatman No.1 paper. This substrate was washed with distilled water until the $\mathrm{pH}$ became 7 . It was then dried in an oven at a temperature of $105{ }^{\circ} \mathrm{C}$ for $6 \mathrm{~h}$ (Nazir et al. 2016). This substrate was then analyzed to assess the degree of delignification.

\section{Degree of delignification and solid recovery}

The degree of delignification was defined as the weight fraction of lignins removed during the pretreatment and was calculated according to Eq. 5,

$$
\mathrm{D}(\%)=\left(\frac{1-L \times m_{\mathrm{pre}}}{L_{0} \times m_{\mathrm{s}}}\right) \times 100
$$

where $L$ is the lignin content in the pretreated biomass (\%), $L_{0}$ is the lignin content in the raw biomass $(\%), m_{\text {pre }}$ is the dry mass of biomass after pretreatment, and $m_{\mathrm{s}}$ is the dry mass of the raw (untreated) biomass used (Dąbkowska-Susfał 2020). Factors considered to be influential as a result of the screening test were subjected to optimization using a central composite design based on the response surface methodology (RSM).

The solid recovery was obtained using alternate ethanol-water extraction (Premkumari et al. 2019).

\section{Central composite design (CCD)}

After the screening step, the influential factors were subjected to a central composite design (CCD) based on the response surface methodology (RSM) to determine the optimal conditions for delignification. Design Expert software (DEMO version 11, 
Stat-Ease, Minneapolis, MN), which is an experimental design tool, was used for this purpose. This methodology induces the formulation of a second order polynomial, which describes the process, as shown in Eq. 6,

$$
Y=b_{0}+\sum b_{i} X_{i}+\sum \sum b_{i j} X_{i} X_{j}+\sum b_{i i} X_{i}^{2}
$$

where $b_{0}$ is the means effect, $b_{\mathrm{i}}$ is the main effects, $b_{\mathrm{ij}}$ is the interaction effects of order 2 , $b_{\text {ii }}$ is the quadratic effects, and $X_{\mathrm{i}}$ and $X_{\mathrm{j}}$ are the coded variables. This equation was shown to be effective in experimental models and will help to study the linear, quadratic, cubic, and interaction effects of factors on the degree of delignification.

\section{Model fit and statistical analysis}

Design Expert software was used to generate the experimental data and develop the regression model. The goodness of fit of the regression model was expressed by the regression coefficients $\left(\mathrm{R}^{2}\right)$, and statistical significance was determined by the Fisher's, Fvalue, $p$-value, and t-test (ANOVA). The response area and the contour lines were both evaluated to estimate the model as well as to determine the optimal levels to fit the second order polynomial equation. Central composite design (CCD) was used to optimize the delignification of cocoa pod husks.

\section{Model validation}

Model validation was based on the analysis of the calculated errors and the coefficient of determination $\left(\mathrm{R}^{2}\right)$ between the results predicted by the model and those obtained experimentally.

\section{Choice of acid for hydrolysis}

Concentrated $\mathrm{HCl}$ and $\mathrm{H}_{2} \mathrm{SO}_{4}$ acids are able to swell and dissolve cellulose (Samah et al. 2011), and the acid hydrolysis is much faster than the enzymatic method (Sharmada et al. 2016). The problem with enzymatic hydrolysis is the poor accessibility of cellulose, due to the rigid association of cellulose with lignin (Mosier et al. 2005; Muharja et al. 2018). Indeed, $90 \%$ of the yield of monosaccharides could be obtained by using concentrated acid pretreatment of the biomass (Palmqvist and Hahn-Hägerdal 2000).

\section{Acid hydrolysis process}

$3 \mathrm{~g}$ of the solid fraction obtained after delignification was subjected to acid hydrolysis (Nazir et al. 2016), by placing the sample in a $250 \mathrm{~mL}$ Erlenmeyer flask and adding a solution of sulfuric acid $\left(\mathrm{H}_{2} \mathrm{SO}_{4}\right)$ to it at a level of $3 \%$ with the ratio of biomass to solvent $(1: 10)$ for $2 \mathrm{~h}$ in an autoclave at $110^{\circ} \mathrm{C}$. After this operation, the hydrolysates were filtered through Whatman No.1 paper and then neutralized with a slow addition of $\mathrm{NaOH}$ for the determination of the reducing sugars.

\section{RESULTS AND DISCUSSIONS}

\section{Initial Lignocellulosic Composition of the Cocoa Pod Husks (CPH)}

Table 3 exbibits the lignocellulosic composition of $\mathrm{CPH}$. The $\mathrm{CPH}$ in the present study were high in carbohydrates and could be alternative candidates to produce platform biomolecules. However, comparing the results of this study with those observed in various studies (Table 3) showed several disparities. These observed differences could be linked to 
geographical factors, the location of the materials collected, different analysis methods, the variety of biomass, differences in the solvents used, or different collection periods as well as to different climatic and storage conditions (Ouattara et al. 2021). In addition, the maturation of a living plant material tends to increase the lignin and lignocellulose contents (Thamsee et al. 2019). The values obtained for all lignocellulosic fibers during this study were close to those of Sandesh et al. (2020). However, these values are much higher than those obtained in other studies (Marsiglia et al. 2016). The cellulose values were close to those generally reported by various literatures (Titiloye et al. 2013; Sandesh et al. 2020). However, they are lower than those reported in a recent study by Nazir et al. (2016). The $\mathrm{CPH}$ in the area of this study therefore have enormous potential for recovery. However, due to their relatively high lignin content $(25.62 \% \pm 4.32 \%)$, adequate pretreatment is necessary for the release of fermentable sugars.

Table 3. Lignocellulosic Composition of the Cocoa Pod Husks (CPH) in Addition to the Results of Several Studies

\begin{tabular}{|c|c|c|c|c|}
\hline Lignin (\%) & Cellulose (\%) & Hemicellulose (\%) & Extractables (\%) & Reference \\
\hline 24.16 & 28.25 & 16.75 & - & (Sandesh et al. 2020) \\
\hline 33.96 & 30.41 & 11.97 & $23.66 \pm 1.77$ & (Titiloye et al. 2013) \\
\hline 18.19 & 23.04 & 38.08 & - & (Asiedu et al. 2019) \\
\hline 34.82 & 44.69 & 11.15 & - & (Nazir et al. 2016) \\
\hline $25.62 \pm 4.32$ & $31.68 \pm 2.07$ & $16.97 \pm 2.07$ & $21.57 \pm 1.04$ & This work \\
\hline
\end{tabular}

\section{Optimization of Cocoa Pod Husk (CPH) Delignification}

The screening of factors and estimation and the statistics of the coefficients relating to delignification

Tables 4 and 5 show the experimental design with the results obtained from the screening plan and the estimation of the factor coefficients, using the NemrodW software, respectively.

The standard deviation of the degree of delignification estimated by the NemrodW software was 1.075. This value validated the chosen experimental field. It therefore appears that the delignification was strongly influenced by the variation of these two factors.

Table 4. Experimental Design and Results of the Screening Plan

\begin{tabular}{|c|c|c|c|c|c|c|}
\hline Assay & $\mathrm{A}(\%)$ & $\mathrm{B}(\%)$ & $\mathrm{C}(\mathrm{h})$ & $\mathrm{D}(\mathrm{min})$ & $\mathrm{E}\left({ }^{\circ} \mathrm{C}\right)$ & Degree of Delignification (Y) (\%) \\
\hline 1 & 5 & 10 & 4 & 15 & 30 & 89.87 \\
\hline 2 & 1 & 10 & 7 & 60 & 30 & 90.15 \\
\hline 3 & 1 & 5 & 7 & 15 & 130 & 85.49 \\
\hline 4 & 5 & 5 & 7 & 60 & 30 & 75.75 \\
\hline 5 & 1 & 10 & 4 & 60 & 130 & 93.00 \\
\hline 6 & 5 & 5 & 4 & 60 & 130 & 86.80 \\
\hline 7 & 5 & 10 & 7 & 15 & 130 & 91.35 \\
\hline 8 & 1 & 5 & 4 & 15 & 30 & 81.43 \\
\hline
\end{tabular}


The statistical analysis of the coefficients illustrated in Table 5 shows that the coefficients $b_{2}$ and $b_{5}$ had sufficient significance to be considered in the optimization process. They reflect the effects of the biomass to solvent ratio and the temperature, respectively.

Table 5. Estimated Coefficients for the Screening Plan

\begin{tabular}{|c|c|c|c|}
\hline Name & Coefficient & Standard Deviation & Significance \\
\hline b0 & 86.730 & 1.075 & Significant \\
\hline b1 & -0.788 & 1.075 & No significant \\
\hline b2 & 4.362 & 1.075 & Significant \\
\hline b3 & -1.045 & 1.075 & No significant \\
\hline b4 & -0.305 & 1.075 & No significant \\
\hline b5 & 2.430 & 1.075 & Significant \\
\hline
\end{tabular}

These results agreed with the results in Shet et al. (2016), which showed that in the optimization of the pretreatment of $\mathrm{CPH}$ with sodium carbonate $\left(\mathrm{Na}_{2} \mathrm{CO}_{3}\right)$, the most significant factor was the biomass to solvent ratio. Given this, this ratio is important in the process of pretreating lignocellulose, since it maintains thermal equilibrium and adjusts the concentration of chemicals and therefore strongly impacts the cost of pretreatment (Xie et al. 2018). The graphic representation of the effects of the factors is illustrated by the diagram of the effects indicated in Fig. 2. By considering the confidence interval of the values of the coefficients (delimited by the two vertical dotted lines), one can affirm that at most two factors are active on the degree of delignification of the cocoa pod husk. These are the biomass to solvent ratio and the temperature.

\begin{tabular}{|c|c|c|c|c|c|}
\hline \multirow[t]{2}{*}{ Name of coefficients } & & \multicolumn{2}{|c|}{ Coefficients values } & \multirow[b]{2}{*}{200} & \multirow[b]{2}{*}{400} \\
\hline & & 400 & $200 \quad 0.00$ & & \\
\hline Solvent concentration & b1 & : & 0 & & \\
\hline Biomass to solvent ratio & b2 & $\vdots$ & & & \\
\hline Contact time & b3 & 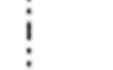 & 1.05[ & & \\
\hline Heating time & b4 & $\vdots$ & .0 .30 & & \\
\hline Temperature & b5 & $\vdots$ & & & 243 \\
\hline
\end{tabular}

Fig. 2. Representation of the effects of factors on the degree of delignification

The observations in this study are consistent with those reported in a recent study by Júnior et al. (2020); it was shown that the reaction time has a negative effect on the pretreatment of waste yerba mate (Ilex paraguariensis) with $\mathrm{KOH}$. This observation revealed that the change of this variable from the lower level to the higher level contributed to a decrease in the response. Consequently, it was appropriate to study these factors in the region of the lowest level (Júnior et al. 2020). 
Analysis of the influence of different factors on the degree of delignification

In addition, the analysis of the coefficients (Table 5) showed that the delignification was significantly increased if a solution with a biomass to solvent ratio of $10 \%$ was treated with $1 \% \mathrm{KOH}$ for $4 \mathrm{~h}$ at room temperature, followed by $15 \mathrm{~min}$ of heating to a temperature of $130{ }^{\circ} \mathrm{C}$.

Experimental design for the optimization of the delignification process

The most significant factors from the screening plan were subjected to optimization in order to intensify the delignification process. For this purpose, the biomass to solvent ratio and the temperature were considered. These two factors were subjected to optimization in order to develop a correlation related to the degree of delignification of the $\mathrm{CPH}$. This design made it possible to experiment with different combinations of biomass to solvent ratios and temperatures. Table 6 shows the coded and actual values of the variables studied in this design.

Table 6. Coded Variables and Actual Levels Used in This Design

\begin{tabular}{|c|c|c|c|c|c|c|}
\hline \multirow{2}{*}{ Variables } & \multirow{2}{*}{ Symbol Coded } & \multicolumn{5}{|c|}{ Levels Coded } \\
\cline { 3 - 7 } & & $-\alpha$ & -1 & 0 & 1 & $+\alpha$ \\
\hline Biomass to solvent ratio $(\% \mathrm{p} / \mathrm{v})$ & $X_{1}$ & 3.96 & 5 & 7.5 & 10 & 11.04 \\
\hline Temperature $\left({ }^{\circ} \mathrm{C}\right)$ & $X_{2}$ & 9.29 & 30 & 80 & 130 & 151.71 \\
\hline
\end{tabular}

Mechanism of delignification and the recovery of solids after the pretreatment of CPH

Table 7 shows that the degree of delignification ranged from $74.9 \%$ to $93.9 \%$, and it continuously increased. While analyzing the results from Table 7 , the values obtained were well above the majority of those reported in the literature for various residues, with a maximum value of $67.5 \%$ that was obtained for elephant grass with a $1 \% \mathrm{KOH}$ pretreatment at a temperature of $121{ }^{\circ} \mathrm{C}$ for $1 \mathrm{~h}$ (Bensah et al. 2019). Likewise, values between $49.7 \%$ and $87.7 \%$ were found for corn straw pretreated with $2 \% \mathrm{KOH}$ at a temperature of $50{ }^{\circ} \mathrm{C}$ (Dąbkowska-Susfał 2020). Table 7 shows that an increase in temperature led to greater delignification and therefore lower solids recovery. This confirms the hypothesis that the alkaline delignification of lignocellulosic residues at high temperatures leads to the solubilization of lignocellulose by breaking the covalent and ester bonds between the constituents. Pretreatments using alkalis at high temperatures causes chemical swelling in the cellulose and induces a saponification reaction, which promotes the cleavage of the ester bonds in the lignocellulosic matrix (Woiciechowski et al. 2020). This leads to an increase in the internal surface area, a decrease in the degree of polymerization and crystallinity, as well as a breakdown of the chemical bonds between the lignins and carbohydrates. This results in the destruction of the lignin structure and also leads to an increase in the porosity of the biomass and its accessibility to subsequent hydrolysis (Woiciechowski et al. 2020).

Usually, pretreatment causes the solubilization of biomass components in the liquid phase, resulting in a loss of solid phase material. However, the extent of the loss depends on the pretreatment conditions (Dąbkowska-Susfał 2020). The solids recovery ranged from $55.6 \%$ to $80.2 \%$, corresponding to tests 8 and 1 , respectively. Similar values were obtained by Premkumari et al. (2019) with cotton swab. They found solids recovery values between $51.7 \%$ and $82.9 \%$ for $2 \% \mathrm{KOH}$ pretreatments at temperatures between 50 and $120{ }^{\circ} \mathrm{C}$. 
Lower values were generally associated with higher temperatures under severe pretreatment conditions. This could be attributed to the partial or total solubilization of the lignins. In addition, the degradation of hemicelluloses can also occur due to its amorphous, heterogeneous, and branched structure with little resistance. This makes it more sensitive to solubilization at higher temperatures than semi-crystalline cellulose under alkaline conditions (Xu and Cheng 2011).

Table 7. Experimental Matrix and the Delignification Results

\begin{tabular}{|c|c|c|c|c|}
\hline Assay & $\begin{array}{c}\text { Biomass to Solvent } \\
\text { Ratio }(\%)(X 1)\end{array}$ & $\begin{array}{c}\text { Temperature }\left({ }^{\circ} \mathrm{C}\right) \\
\left(X_{2}\right)\end{array}$ & $\begin{array}{c}\text { Degree of } \\
\text { Delignification }(\%)\end{array}$ & $\begin{array}{c}\text { Solid Recovery } \\
(\%)\end{array}$ \\
\hline 1 & -1 & -1 & 75.6225 & 80.179 \\
\hline 2 & 1 & -1 & 87.9662 & 77.381 \\
\hline 3 & -1 & 1 & 85.7900 & 75.299 \\
\hline 4 & 1 & 1 & 93.8675 & 77.135 \\
\hline 5 & -1.41421 & 0 & 74.9004 & 66.530 \\
\hline 6 & 1.41421 & 0 & 91.1809 & 63.814 \\
\hline 7 & 0 & -1.41421 & 86.2565 & 79.716 \\
\hline 8 & 0 & 1.41421 & 92.5554 & 55.572 \\
\hline 9 & 0 & 0 & 86.2325 & 73.837 \\
\hline 10 & 0 & 0 & 89.8481 & 70.852 \\
\hline 11 & 0 & 0 & 90.7439 & 78.672 \\
\hline 12 & 0 & 0 & 90.7825 & 78.344 \\
\hline 13 & 0 & 0 & 90.7792 & 79.955 \\
\hline
\end{tabular}

The results of the delignification process obtained at the end of the pretreatment study were subjected to an analysis of variance (ANOVA) using Design Expert software.

Choice of the model for optimizing the delignification process

Table 8 shows that the quadratic model would be the most appropriate for predicting the delignification process of $\mathrm{CPH}$. The predicted $\mathrm{R}^{2}$ of this model $(0.815)$ is in agreement with the adjusted $\mathrm{R}^{2}(0.907)$. This means that more than $90.66 \%$ of the observed values could be explained by the model and the rest is the residual. Therefore, this model bodes well for providing a good prediction of the degree of delignification of these residues.

Table 8. Summary Statistics of the Model

\begin{tabular}{|c|c|c|c|c|c|c|c|c|c|}
\hline Model & $\begin{array}{c}\text { Std. } \\
\text { Dev. }\end{array}$ & $\mathrm{R}^{2}$ & $\begin{array}{c}\text { Adjusted } \\
\mathrm{R}^{2}\end{array}$ & $\begin{array}{c}\text { Predicted } \\
\mathrm{R}^{2}\end{array}$ & Df & PRESS & $\begin{array}{c}\mathrm{F} \text { - } \\
\text { value }\end{array}$ & $p$-value & Suggestion \\
\hline Linear & 3.310 & 0.742 & 0.690 & 0.529 & 6 & 199.15 & 4.05 & 0.0987 & \\
\hline 2FI & 3.410 & 0.752 & 0.669 & 0.441 & 5 & 236.56 & 4.62 & 0.0817 & \\
\hline Quadratic & $\mathbf{1 . 8 2 0}$ & $\mathbf{0 . 9 4 6}$ & $\mathbf{0 . 9 0 7}$ & $\mathbf{0 . 8 1 5}$ & $\mathbf{3}$ & $\mathbf{7 8 . 1 8}$ & $\mathbf{0 . 6 5 5}$ & $\mathbf{0 . 6 2 1}$ & Suggested \\
\hline Cubic & 1.780 & 0.963 & 0.910 & 0.892 & 1 & 45.88 & 0.088 & 0.782 & Aliased \\
\hline
\end{tabular}

\section{Suggested model equation}

Regression equation generated by the Design Expert software translates, degree of delignification $(Y)$ as a function of independent variables $\left(X_{1}\right.$ and $\left.X_{2}\right)$, which correspond to the biomass to solvent ratio and the temperature, respectively and their linear and quadratic interactions, expressed by a second order polynomial, shown in Eq. 7, 


$$
Y=31.86872+11.06579 X_{1}+0.141704 X_{2}-0.547396 X_{11}
$$

Analysis of variance (ANOVA) for the suggested quadratic model

According to Table 9 , the $p$-value of the model is 0.0003 , which is less than 0.0500 , with a high F-value (24.29).

In addition, the F-value (0.6547) of the lack of fit implies that it is insignificant. However, a good model must have a significant regression and an insignificant lack of fit (Júnior et al. 2020). Moreover, the $p$-values of the terms $X_{1}, X_{2}$, and $X_{12}$ of the model are all less than 0.0500 , also showing their significance at $95 \%$.

Table 9. Statistical Analysis of the Suggested Quadratic Model

\begin{tabular}{|c|c|c|c|c|c|c|}
\hline Source of Variation & $\begin{array}{c}\text { Sum of } \\
\text { Squares }\end{array}$ & Df & Mean Square & F-value & $p$-value & Significance \\
\hline Model & 400.20 & 5 & 80.04 & 24.29 & 0.0003 & Significant \\
\hline $\begin{array}{c}\text { Biomass to solvent } \\
\text { ratio }\left(X_{1}\right)\end{array}$ & 235.94 & 1 & 235.94 & 71.60 & $6.35844 \mathrm{E}-05$ & \\
\hline Temperature $\left(X_{2}\right)$ & 77.98 & 1 & 77.98 & 23.67 & 0.0018 & \\
\hline$X_{1} X_{2}$ & 4.55 & 1 & 4.55 & 1.38 & 0.2784 & \\
\hline$X_{1}{ }^{2}$ & 81.42 & 1 & 81.42 & 24.71 & 0.0016 & \\
\hline$X_{2}{ }^{2}$ & 0.3959 & 1 & 0.3959 & 0.1202 & 0.7390 & \\
\hline Residual & 23.06 & 7 & 3.29 & - & - & Not \\
\hline Lack of Fit & 7.60 & 3 & 2.53 & 0.6547 & 0.6209 & significant \\
\hline Pure Error & 15.47 & 4 & 3.87 & - & - & \\
\hline Cor Total & 423.26 & 12 & - & - & - & \\
\hline
\end{tabular}

Influence of the independent variables on the degree of delignification

Response surface methodology can be described as a graphical representation of the equations from the data analysis (Rachmawaty et al. 2019). It is very useful for assessing the importance of several factors, especially those that involve complex interactions (Wasli et al. 2009). In this context, the optimal levels of the variables were determined by plotting the three-dimensional and two-dimensional surface plots (Fig. 3), which were based on Eq. 7. 


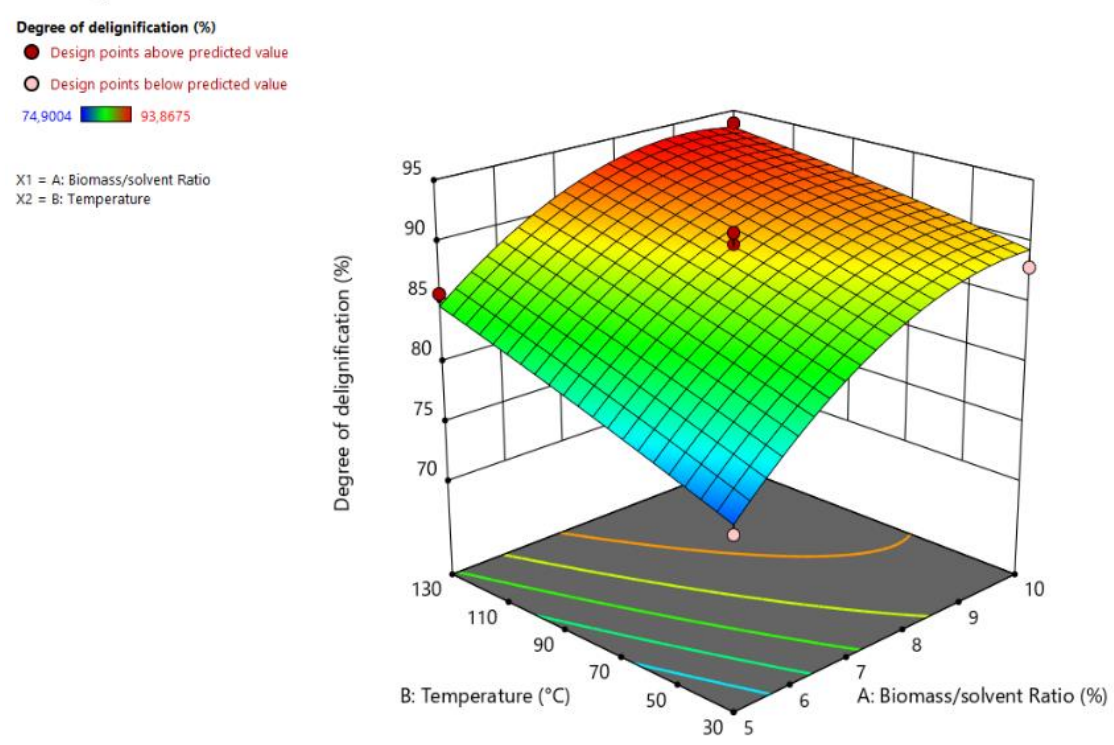

Fig. 3. Surface $(3 \mathrm{D})$ plot showing the effect of the temperature and biomass to solvent ratio on the degree of delignification of $\mathrm{CPH}$

The degree of delignification shows a quadratic dependence of the biomass to solvent ratio with a high effect of the term $\mathrm{X}_{1}^{2}$ ( $\mathrm{p}$-value less than 0.05 ). These results were consistent with the results of Alexander et al. (2020), who demonstrated the importance of the volume of the solvent. The increase in the degree of delignification as the biomass to solvent ratio increased could be explained by the availability of $\mathrm{KOH}$ for pretreatment. Since the $\mathrm{KOH}$ concentration in this study was set at $1 \%$ with a working volume of $50 \mathrm{~mL}$ for all samples, increasing this ratio would thus promote greater delignification until saturation of the substrate-solvent system. This leads to a considerable reduction in the mass transfer rate (Alexander et al. 2020). In addition, a similar trend was observed with CPH for production (Shet et al. 2018).

An increase in temperature from the range of 30 to $130{ }^{\circ} \mathrm{C}$ results in a continual increase in the degree of delignification from $74.9 \%$ to $93.87 \%$. This observation was in accordance with the results of Bensah et al. (2019) and Souza et al. (2020), which have shown that a high temperature leads to greater delignification under alkaline conditions. However, a weak interaction effect between the biomass to solvent ratio and the temperature was observed, with a high $p$-value $(0.2784$ is greater than 0.05$)$, showing that a simultaneous increase in these two variables would lead to a decrease in the degree of delignification. This was confirmed by the antagonistic effect of the negative coefficient for the $X_{1} X_{2}$ interaction term on the response and could be attributed to a limiting effect of the pretreatment reagent relative to the biomass in the reactor.

\section{Optimal delignification conditions}

In order to optimize responses, a useful approach is the desirability function methodology (Derringer and Suich 1980). This approach is used to optimize responses by inspecting the response model and adjusting the observed responses using a second order equation based on the levels of the independent variables (Shet et al. 2018). In this approach, the response $Y_{\mathrm{i}}$ is converted into an individual desirability function $\left(d_{\mathrm{i}}\right)$. This function varies in the range of 0 to 1 , with 0 being a totally undesirable response value and 1 being a perfectly desirable or ideal response value. Based on this, with the constraints 
that the pretreatment parameters were within range and that the delignification achieved was maximal, the optimized conditions were a biomass to solvent ratio of $9.14 \%$, with a $1 \% \mathrm{KOH}$ pretreatment for $4 \mathrm{~h}$ at a temperature of $30^{\circ} \mathrm{C}$ and autoclaved at a temperature of $128.3{ }^{\circ} \mathrm{C}$ for $15 \mathrm{~min}$, with $93.9 \%$ of delignification. Furthermore, optimal conditions for $\mathrm{CPH}$ delignification, using $5 \%(\mathrm{w} / \mathrm{v}) \mathrm{NaOH}$ and a biomass to solvent ratio of 1:10 coupled with microwave heating have been reported (Ahmad et al. 2021), reaching 86.6\% of delignification. Likewise, the $\mathrm{CPH}$ was pretreated with a biomass to solvent ratio of $10 \%$ in an aqueous solution of $0.75 \% \mathrm{w} / \mathrm{v} \mathrm{NaOH}$ and autoclaved at a temperature of $121{ }^{\circ} \mathrm{C}$ for 20 min, reaching 43.8\% of delignification (Ward-Doria et al. 2016). A study by Akhtar et al. (2014) showed that a large amount of $71.9 \%$ of lignin was removed by microwave assisted alkaline/acid pretreatment compared to conventional heating (34.6\%). In a recent study, the orange peel was exposed to a conventional alkaline and ultrasonically assisted pretreatment at room temperature reaching $86 \%$ delignification and $92 \%$ delignification in $4 \mathrm{~h}$ respectively, with a maximum reducing sugars of $1.30 \mathrm{~g} / \mathrm{L}$ in $6 \mathrm{~h}$ of treatment after enzymatic hydrolysis; compared to the conventional method where the sugar concentration was $0.814 \mathrm{~g} / \mathrm{L}$ in $24 \mathrm{~h}$ (Utekar et al. 2021). Likewise, the effect of $\mathrm{KOH}$ was evaluated on other substrates, for cotton swab $\left(120{ }^{\circ} \mathrm{C}\right.$ for $1 \mathrm{~h}$ with $3 \% \mathrm{KOH}$, giving $\left.68.9 \%\right)$ of delignification (Premkumari et al. 2019), corn straw (With conventional heating at $50^{\circ} \mathrm{C}$ for $24 \mathrm{~h}$ with $2 \% \mathrm{KOH}$, with $87.7 \%$ ) of delignification (Dąbkowska-Susfał 2020).

\section{Validation of the model using the analysis of the residuals and the coefficient $\mathrm{R}^{2}$}

Figure 4A shows the degree of delignification observed $(Y \exp )$ compared to the predicted value ( $Y_{\text {Pred }}$ ). The data predicted by the model were close to those observed. This was shown by the points grouped around the regression line. Moreover, the predicted value $\left(R^{2}=0.8153\right)$ was in reasonable agreement with the adjusted $R^{2}(0.906)$.

Figure 4B shows a random distribution of the residual plots of the model without any trend. This indicated good predictions of the maximum response and the fit of the model (Qi et al. 2009). It can be deduced that the degree of delignification of CPH using $\mathrm{KOH}$ could be obtained thanks to the punctual prediction capacity of the software.
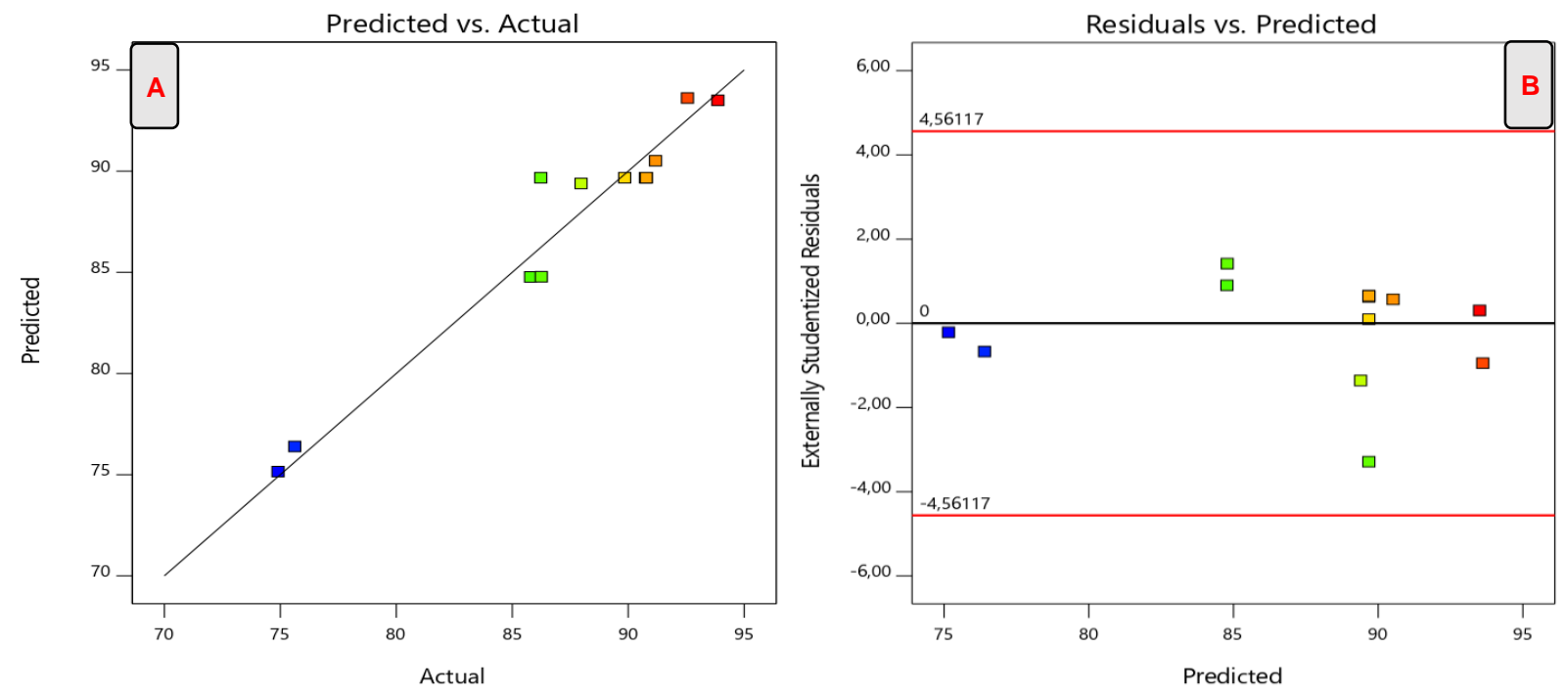

Fig. 4. The degree of delignification observed and predicted by the model $(A)$ and the residuals as a function of the predicted response (B) 
This hypothesis seems to be confirmed by the calculation of the residual error as well as by the percentage error compared for five points carried out under the optimized conditions (Table 10).

Table 10. Results of the Validation Tests

\begin{tabular}{|c|c|c|c|c|c|c|}
\hline Assay & $\begin{array}{c}\text { Biomass to } \\
\text { Solvent Ratio }(\%)\end{array}$ & $\begin{array}{c}\text { Temperature } \\
\left({ }^{\circ} \mathrm{C}\right)\end{array}$ & $\begin{array}{c}\text { Experimental } \\
\text { Value }(\%)\end{array}$ & $\begin{array}{c}\text { Predicted } \\
\text { Value }(\%)\end{array}$ & Residual & $\begin{array}{c}\text { Error } \\
(\%)\end{array}$ \\
\hline 1 & 9.143 & 128.300 & 94.262 & 93.936 & 0.326 & 0.346 \\
\hline 2 & 8.939 & 129.200 & 95.017 & 93.884 & 1.133 & 1.192 \\
\hline 3 & 9.281 & 128.750 & 94.866 & 93.906 & 0.960 & 1.012 \\
\hline 4 & 9.258 & 129.000 & 94.902 & 93.899 & 1.003 & 1.057 \\
\hline 5 & 9.357 & 129.200 & 93.916 & 93.886 & 0.030 & 0.032 \\
\hline
\end{tabular}

The error percentage ranged from $0.032 \%$ to $1.192 \%$, which were all less than $5 \%$. Therefore, the model appears accurate, and the analysis of the response surface methodology can be a useful technique for predicting and optimizing the delignification.

\section{Estimation of the Composition of the CPH After Delignification Using $\mathrm{KOH}$}

Figure 5 shows the changes caused in the lignocellulosic composition of CPH under the impact of $\mathrm{KOH}$. This figure shows a dramatic reduction in lignin content, indicating that $\mathrm{KOH}$ had a major effect on breaking down the lignin structure.

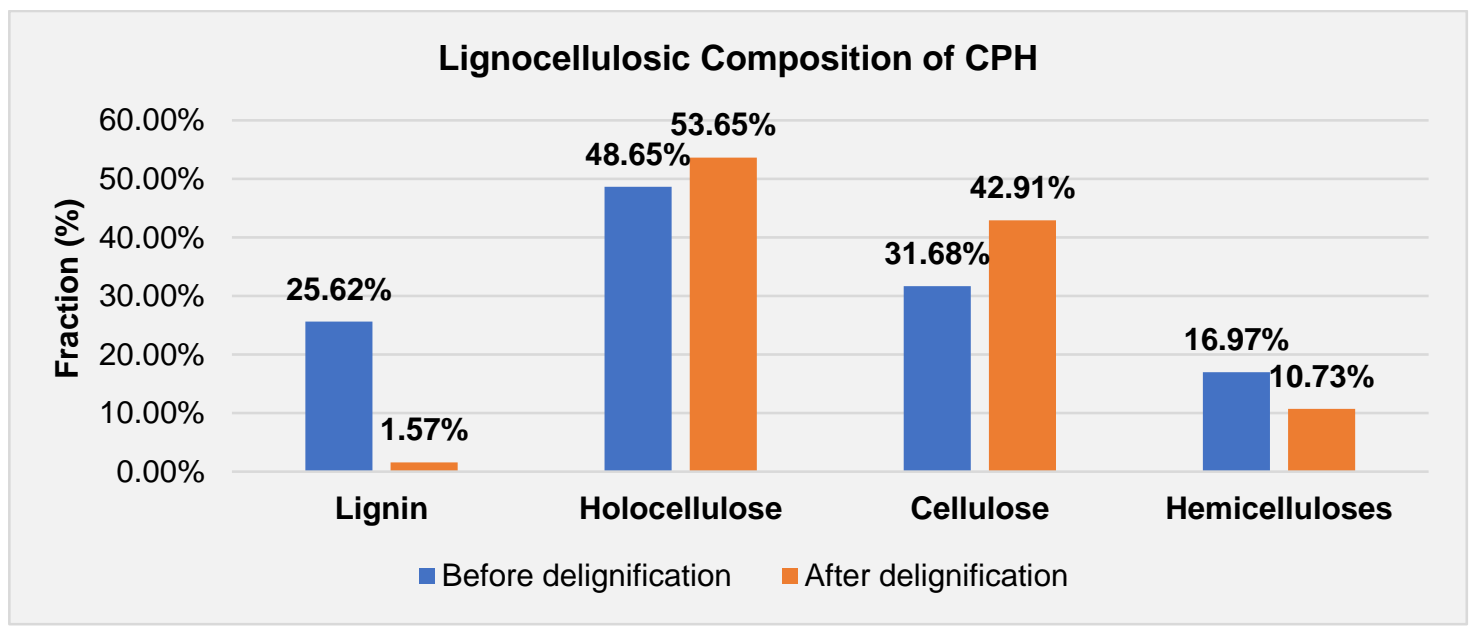

Fig. 5. Lignocellulosic composition of $\mathrm{CPH}$ before and after delignification

Likewise, an increase in the cellulosic fraction was observed to the detriment of that of hemicelluloses. This could be explained by the fact that at elevated temperature and in an alkaline environment, there is increased dissolution of lignin, hemicelluloses, extractables (Bensah et al.2019).

\section{Estimation of Total Phenolic Content and Reducing Sugars from CPH}

Figure 6 shows the contents of total phenolic compounds resulting from delignification, and the contents of reducing sugars obtained after acid hydrolysis $(3 \%, \mathrm{v} / \mathrm{v}$, $\mathrm{H}_{2} \mathrm{SO}_{4}$, autoclave, $110{ }^{\circ} \mathrm{C}, 2 \mathrm{~h}$ ), of the raw and extracted samples. A significant reduction $(55.6 \%)$ in the levels of total phenolics was observed $(116.55 \pm 0.01$ to $51.75 \pm 0.007$ $\mathrm{mg} / \mathrm{mL})$. 


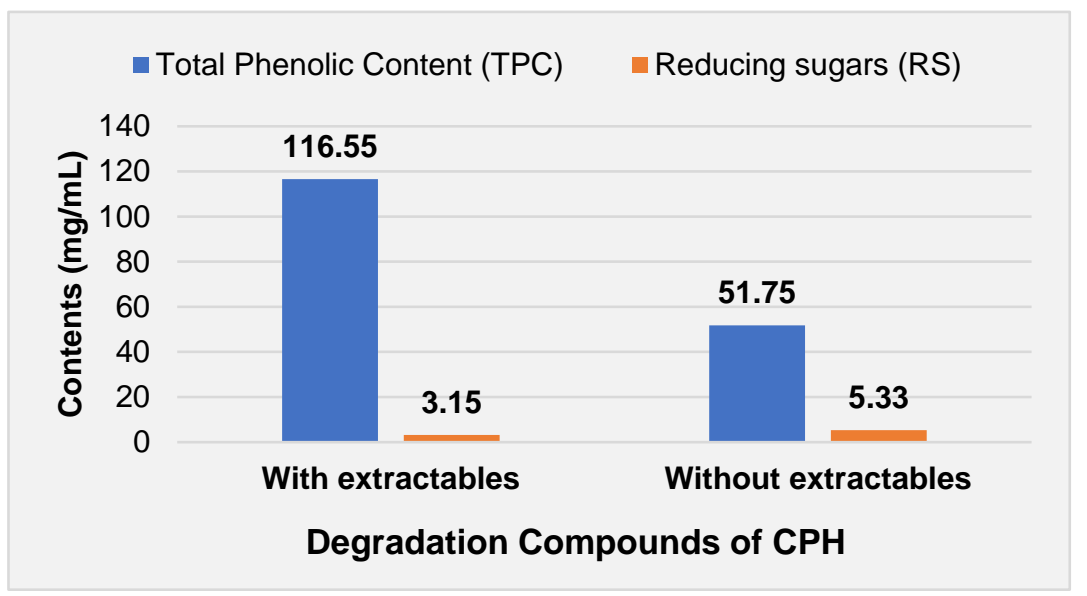

Fig. 6. Effect of extractables on the degradation products of $\mathrm{CPH}$

These values suggest that some of the lignins may have been solubilized into phenolic degradation components (Asghar 2017) by the water-ethanol mixture during the removal of extractables. Therefore, a strong effect of $\mathrm{KOH}$ and an improvement in the subsequent acid hydrolysis was found. This improved the content of reducing sugars to $5.33 \pm 0.143 \mathrm{mg} / \mathrm{mL}$. Furthermore, Shet et al. (2018) reported lower values $(4.09 \mathrm{mg} / \mathrm{mL})$ of reducing sugars from $8.36 \% \mathrm{w} / \mathrm{v} \mathrm{CPH}$ hydrolyzate, using $3.6 \mathrm{~N} \mathrm{HCl}$ at room temperature.

\section{Effect of the KOH Pretreatment on the Morphology and Crystallinity of $\mathrm{CPH}$} Morphological study of cocoa pod husk (CPH)

Micrographs of the non-pretreated (B) and pretreated (P) CPH are shown in Fig. 7.
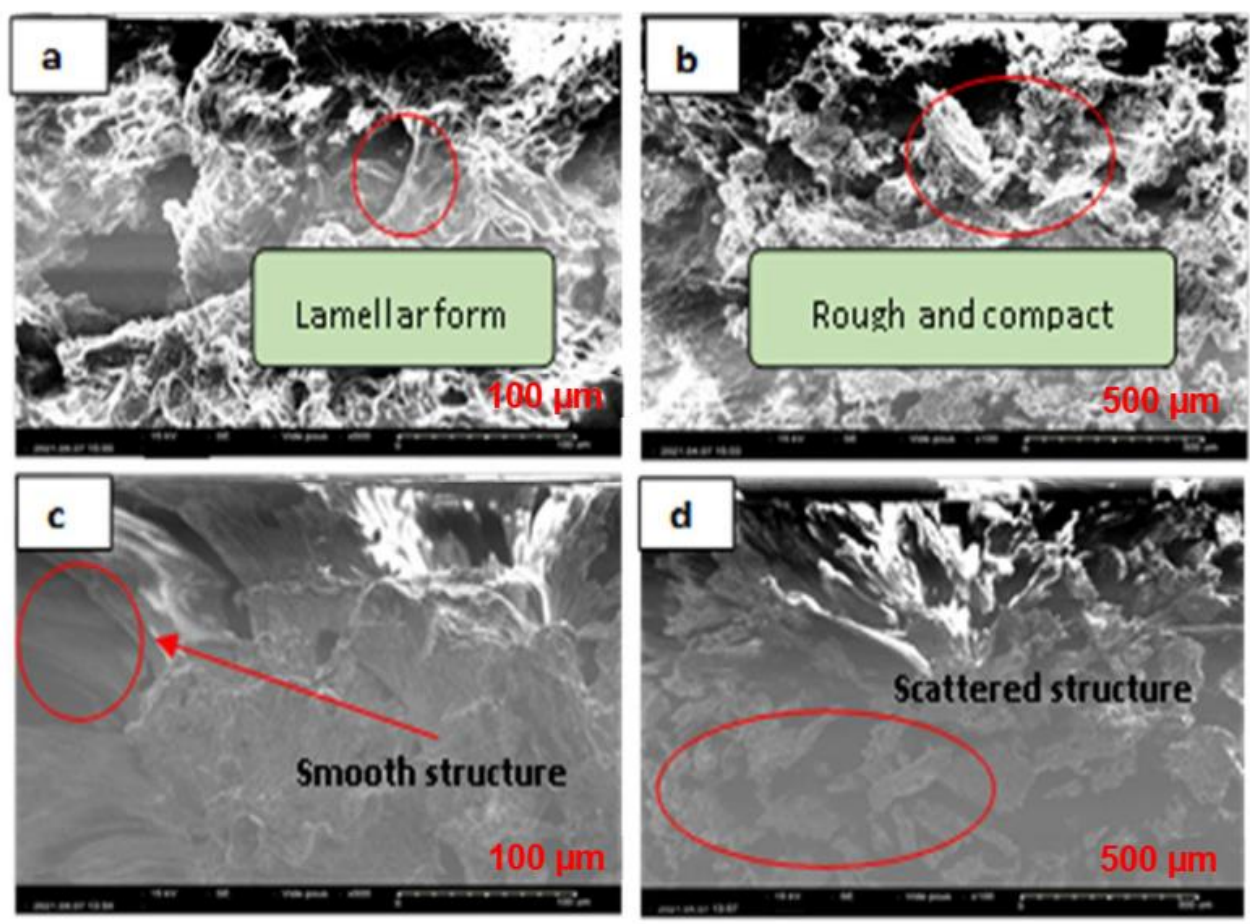

Fig. 7. Electron micrograph of the raw ( $a$ and $b)$ and pretreated ( $c$ and d) $\mathrm{CPH}$ 
Figure $7 \mathrm{a}$ and $7 \mathrm{~b}$ present a rough and compact structure, composed of particles in lamellar form. The individual lignocellulosic structure of the crude CPH is not visible. This could be due to the presence of extractables, e.g., waxes, fats, pectins, polyphenols, and other impurities (Daud et al. 2013). However, the removal of these extractables (21.57 \pm $1.04 \%$ ) using the alternate ethanol-water treatment allowed better exposure of the lignins to alkaline attack. Thus, the pretreated $\mathrm{CPH}$ (Fig. 6c and 6d) appears smoother and has a dispersed and irregular structure, showing that the $\mathrm{KOH}$ has broken several bonds within the components; this was confirmed by the presence of several visible cavities.

$X$-ray diffraction (XRD) analysis and crystallinity of the cocoa pod husk (CPH)

Figure 8 shows the XRD diffractograms of pretreated and non-pretreated $\mathrm{CPH}$. Additionally, Fig. 8 shows almost similar XRD shapes for untreated and processed samples, producing specific peaks at $2 \theta=22.10^{\circ}$ and $22.32^{\circ}$. The amorphous background was characterized by a low intensity of diffraction at $2 \theta$ of between $18.30^{\circ}$ and $18.86^{\circ}$. These peaks confirm the presence of a highly controlled crystalline and amorphous cellulosic structure, respectively (Memon and Memon 2020).

The peak at $2 \theta=22.32^{\circ}$ in the diffractogram of the pretreated $\mathrm{CPH}$ is narrower and more intense than the peak in the untreated $\mathrm{CPH}$. This could be due to the dissolution of amorphous hemicelluloses and lignin components in $\mathrm{CPH}$.

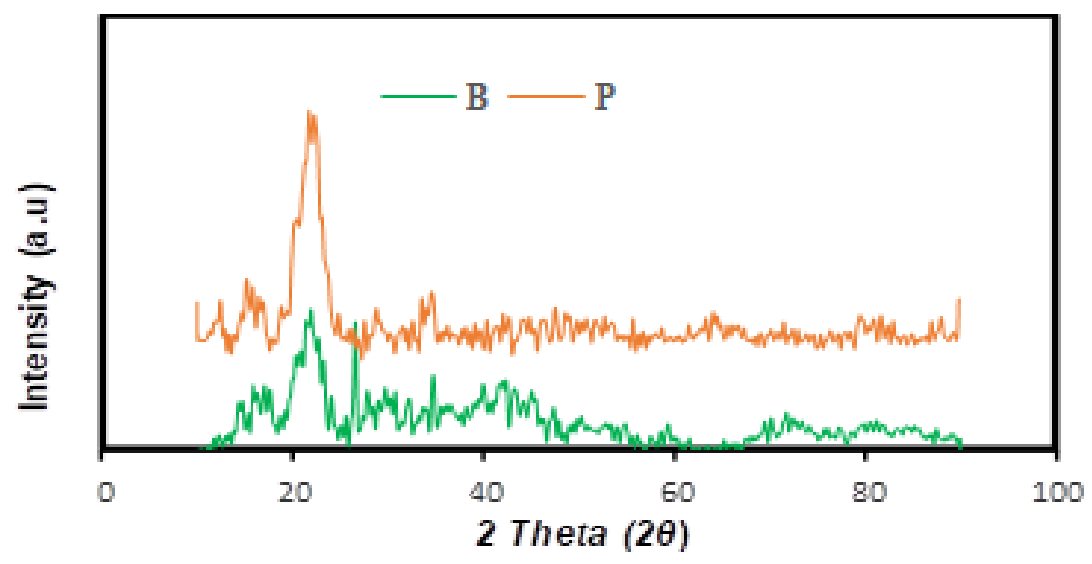

Fig. 8. XRD spectrum of the untreated $(B)$ and treated $(P) C P H$

Table 11 shows the crystallinity index of untreated and pretreated $\mathrm{CPH}$ calculated from X-ray diffraction profiles. The degree of crystallinity obtained (65.2\%) after delignification is close to that of crystalline cellulose obtained in other work (Akinjokun et al. 2021). But the value was lower than that obtained by (Lubis et al. 2018), which is 74\%. A decrease in crystallinity after $\mathrm{KOH}$ treatment under optimized conditions was also observed. This finding has already been made in the studies of He et al. (2008) and Rambat et al. (2015) and could be due to the fact that optimized delignification with $\mathrm{KOH}$ not only removed lignins and some amorphous hemicelluloses, but also caused the destruction of some cellulosic crystalline areas of $\mathrm{CPH}$ by breaking cellulose chains during of the pretreatment process (Muharja et al. 2018). 
Table 11. Crystallinity Index of the Crude and Pretreated $\mathrm{CPH}$

\begin{tabular}{|c|c|c|c|}
\hline Samples & $I_{002}\left(2 \theta=22.10\right.$ to $\left.22.32^{\circ}\right)$ & $I_{\mathrm{am}}\left(2 \theta=18.30\right.$ to $\left.18.86^{\circ}\right)$ & $\mathrm{Crl}(\%)$ \\
\hline $\mathrm{CPH}$ untreated $(\mathrm{B})$ & 22.01 & 04.55 & 79.33 \\
\hline $\mathrm{CPH}$ treated $(\mathrm{P})$ & 56.06 & 19.50 & 65.22 \\
\hline
\end{tabular}

In addition, this delignification resulted in an enlargement of the ratio of pores and internal surfaces (He et al. 2008). This will have the advantage of promoting access to sulfuric acid for subsequent hydrolysis into fermentable sugars, used for fermentation into bioproducts.

\section{CONCLUSIONS}

1. The alkaline pretreatment under autoclave heating showed an improvement of the delignification process, which allowed for a reduced time. The optimized conditions were a biomass to solvent ratio of $9.14 \%$, with a $1 \% \mathrm{KOH}$ pretreatment for $4 \mathrm{~h}$ at a temperature of $30{ }^{\circ} \mathrm{C}$ and autoclaved at a temperature of $128.3^{\circ} \mathrm{C}$ for $15 \mathrm{~min}$. The maximum degree of delignification was $93.9 \%$. This delignification was characterized by a decrease in the content of lignin and hemicellulose, but there was a slight increase in the cellulose.

2. This study, which could be the first of its kind, has shown that the extraction of extractables (total phenolic compounds) at around 55.6\%, before delignification using $\mathrm{KOH}$, is an effective strategy to facilitate the delignification of lignocellulosic residues, such as cocoa pod husks and improve their saccharification.

3. A value of $5.33 \mathrm{~g} / \mathrm{L} \pm 0.14 \mathrm{~g} / \mathrm{L}$ in reducing sugars, three times greater than the value before delignification, shows that the results of this study could serve as a basis for the fermentative production of bioproducts.

\section{ACKNOWLEDGMENTS}

The authors would like to thank the International Development Research Center of Canada and the French Development Agency for their invaluable financial support. In accordance with ethical standards.

\section{REFERENCES CITED}

Akhtar, J., Idris, A., Teo, C. L., Lai, L. W., Hassan, N., and Khan, M. I. (2014).

"Comparison of delignification of oil palm empty fruit bunch (EFB) by microwave assisted alkali/acid pretreatment and conventional pretreatment method," International Journal of Advances in Chemical Engineering and Biological Sciences 1(2), 155-157.

Akinjokun, A. I., Petrik, L. F., Ogunfowokan, A. O., Ajao, J., and Ojumu, T. V. (2021). "Isolation and characterization of nanocrystalline cellulose from cocoa pod husk (CPH) biomass wastes," Heliyon 7(4), 1-7. DOI: 10.1016/j.heliyon.2021.e06680 
Alexander, R. A., Innasimuthu, G. M., Rajaram, S. K., Jeganathan, P. M., and Chellam Somasundarar, S. (2020). "Process optimization of microwave-assisted alkali pretreatment for enhanced delignification of Prosopis juliflora biomass," Environmental Progress \& Sustainable Energy 39(1), 1-31. DOI: 10.1002/ep.13289

Arenas-Cárdenas, P., López-López, A., Moeller-Chávez, G. E., and León-Becerril, E. (2017). "Current pretreatments of lignocellulosic residues in the production of bioethanol," Waste and Biomass Valorization 8(1), 161-181. DOI: 10.1007/s12649016-9559-4

Asghar, U. (2017). "Effect of $\mathrm{KOH}$ pretreatment on lignocellulosic waste to be used as substrate for ethanol production," Iranian Journal of Science and Technology, Transactions A: Science 41(3), 659-663. DOI: 10.1007/s40995-017-0284-Z

Asiedu, N. Y., Neba, F. A., and Addo, A. (2019). "Modeling the attainable regions for catalytic oxidation of renewable biomass to specialty chemicals: Waste biomass to carboxylic acids," South African Journal of Chemical Engineering 30, 1-14. DOI: 10.1016/j.sajce.2019.07.003

Bensah, E. C., and Mensah, M. (2013). "Chemical pretreatment methods for the production of cellulosic ethanol: Technologies and innovations," International Journal of Chemical Engineering 2013, 1-22. DOI: 10.1155/2013/719607

Bensah, E. C., and Mensah, M. Y. (2018). "Emerging physico-chemical methods for biomass pretreatment," in: Fuel Ethanol Production from Sugarcane, T. P. Basso and L. C. Basso (ed.), IntechOpen, London, United Kingdom.

Bensah, E. C., Kádár, Z., and Mensah, M. Y. (2019). "Alkali and glycerol pretreatment of West African biomass for production of sugars and ethanol," Bioresource Technology Reports 6, 123-130. DOI: 10.1016/j.biteb.2019.02.013

Boudjema, H. L. (2016). Elaboration de Matériaux Composites Biodégradables Issus de Ressources Renouvelables [Development of Biodegradable Composite Materials from Renewable Resources], Ph.D. Dissertation, University of Oran 2 Mohamed Ben Ahmed, Bir El Djir, Algeria.

Bourahli, M. E. H. (2018). Caractérisation d'un Composite Verre/Époxy [Characterization of a Glass / Epoxy Composite], Ph.D. Dissertation, University Ferhat Abbas of Setif, Sétif, Algeria.

Campos-Vega, R., Nieto-Figueroa, K. H., and Oomah, B. D. (2018). "Cocoa (Theobroma cacao L.) pod husk: Renewable source of bioactive compounds," Trends in Food Science \& Technology 81, 172-184. DOI: 10.1016/j.tifs.2018.09.022

Cruz, G., Pirilä, M., Huuhtanen, M., Carrión, L., Alvarenga, E., and Keiski, R. L. (2012). "Production of activated carbon from cocoa (Theobroma cacao) pod husk," Journal of Civil \& Environmental Engineering 2(2), 1-6. DOI: 10.4172/2165-784X.1000109

Dąbkowska-Susfał, K. (2020). "Efficiency of corn and poplar biomass saccharification after pretreatment with potassium hydroxide," Ecological Chemistry and Engineering $S$ 27(1), 41-53. DOI: 10.2478/eces-2020-0002

Dahunsi, S. O., Adesulu-Dahunsi, A. T., and Izebere, J. O. (2019a). “Cleaner energy through liquefaction of cocoa (Theobroma cacao) pod husk: Pretreatment and process optimization," Journal of Cleaner Production 226, 578-588. DOI:

10.1016/j.jclepro.2019.04.112

Dahunsi, S. O., Osueke, C. O., Olayanju, T. M. A., and Lawal, A. I. (2019b). "Codigestion of Theobroma cacao (cocoa) pod husk and poultry manure for energy generation: Effects of pretreatment methods," Bioresource Technology 283, 229-241. DOI: 10.1016/j.biortech.2019.03.093 
Daud, Z., Kassim, A. S. M., Aripin, A. M., Awang, H., and Hatta, M. Z. M. (2013). "Chemical composition and morphological of cocoa pod husks and cassava peels for pulp and paper production," Australian Journal of Basic and Applied Sciences 7(9), 406-411.

Derringer, G., and Suich, R. (1980). "Simultaneous optimization of several response variables," Journal of Quality Technology 12(4), 214-219. DOI: 10.1080/00224065.1980.11980968

Ghazanfar, M., Irfan, M., and Nadeem, M. (2018). "Statistical modeling and optimization of pretreatment of Bombax ceiba with $\mathrm{KOH}$ through Box-Behnken design of response surface methodology," Energy Sources, Part A: Recovery, Utilization, and Environmental Effects 40(9), 1114-1124. DOI: 10.1080/15567036.2018.1474291

He, Y., Pang, Y., Liu, Y., Li, X., and Wang, K. (2008). "Physicochemical characterization of rice straw pretreated with sodium hydroxide in the solid state for enhancing biogas production," Energy \& Fuels 22(4), 2775-2781. DOI: $10.1021 /$ ef8000967

International Cocoa Organization (ICCO) (2019). "May 2019 quarterly bulletin of cocoa statistics," (https://www.icco.org/may-2019-quarterly-bulletin-of-cocoa-statistics-3/), accessed 10 September 2020.

Jönsson, L. J., and Martín, C. (2016). "Pretreatment of lignocellulose: Formation of inhibitory by-products and strategies for minimizing their effects," Bioresource Technology 199, 103-112. DOI: 10.1016/j.biortech.2015.10.009

Jung, J. Y., Ha, S. Y., Park, J. H., and Yang, J.-K. (2017). “Optimization of alkali pretreatment from steam exploded barley husk to enhance glucose fraction using response surface methodology," Journal of the Korean Wood Science and Technology 45(2), 182-194. DOI: 10.5658/WOOD.2017.45.2.182

Júnior, A. D. N. F., Etchelet, M. I., Braga, A. F. M., Clavijo, L., Loaces, I., Noya, F., and Etchebehere, C. (2020). "Alkaline pretreatment of yerba mate (Ilex paraguariensis) waste for unlocking low-cost cellulosic biofuel," Fuel 266, 1-10. DOI: 10.1016/j.fuel.2020.117068

Lee, J. W., Kim, H. U., Choi, S., Yi, J., and Lee, S. Y. (2011). "Microbial production of building block chemicals and polymers," Current Opinion in Biotechnology 22(6), 758-767. DOI: 10.1016/j.copbio.2011.02.011

Lubis, M., Gana, A., Maysarah, S., Ginting, M. H. S., and Harahap, M. B. (2018). "Production of bioplastic from jackfruit seed starch (Artocarpus heterophyllus) reinforced with microcrystalline cellulose from cocoa pod husk (Theobroma cacao L.) using glycerol as plasticizer," in: IOP Conference Series: Materials Science and Engineering, IOP Publishing, 012100.

Mansur, D., Tago, T., Masuda, T., and Abimanyu, H. (2014). "Conversion of cacao pod husks by pyrolysis and catalytic reaction to produce useful chemicals," Biomass and Bioenergy 66, 275-285. DOI: 10.1016/j.biombioe.2014.03.065

Marsiglia, D. E, Ojeda K. A, Ramírez M. C, and Sánchez, E. (2016). "Pectin extraction from cocoa pod husk (Theobroma cacao L.) by hydrolysis with citric and acetic acid," International Journal of ChemTech Research 9(7), 497-507.

Memon, M. J., and Memon, A. R. (2020). "Wheat straw optimization via its efficient pretreatment for improved biogas production," Civil Engineering Journal 6(6), 10561063. DOI: $10.28991 /$ cej-2020-03091528

Miller, G. L. (1959). "Use of dinitrosalicylic acid reagent for determination of reducing 
sugar," Analytical Chemistry 31(3), 426-428. DOI: 10.1021/ac60147a030

Mosier, N., Hendrickson, R., Ho, N., Sedlak, M., and Ladisch, M. R. (2005).

"Optimization of $\mathrm{pH}$ controlled liquid hot water pretreatment of corn stover,"

Bioresource Technology 96(18), 1986-1993. DOI10.1016/j.biortech.2005.01.013

Muharja, M., Junianti, F., Ranggina, D., Nurtono, T., and Widjaja, A. (2018). “An

integrated green process: Subcritical water, enzymatic hydrolysis, and fermentation,

for biohydrogen production from coconut husk," Bioresource Technology 249, 268-

275. DOI: 10.1016/j.biortech.2017.10.024

Nazir, N., Novelina, Juita, E., Amelia, C., and Fatli, R. (2016). "Optimization of pretreatment process of cocoa pod husk using various chemical solvents," International Journal on Advanced Science, Engineering, and Information Technology 6(3), 403409. DOI: 10.18517/ijaseit.6.3.848

Ong, L. G. A., Chuah, C., and Chew, A. L. (2010). "Comparison of sodium hydroxide and potassium hydroxide followed by heat treatment on rice straw for cellulase production under solid state fermentation," Journal of Applied Sciences 10(21), 6164. DOI: $10.3923 /$ jas.2010.2608.2612

Ouattara, L. Y., Kouassi, E. K. A., Soro, D., Soro, Y., Yao, K. B., Adouby, K., Drogui, A. P., Tyagi, D. R., and Aina, P. M. (2021). "Cocoa pod husks as potential sources of renewable high-value-added products: A review of current valorizations and future prospects," BioResources 16(1), 1988-2020. DOI: 10.15376/biores.16.1.Ouattara

Paixão, S. M., Ladeira, S. A., Silva, T. P., Arez, B. F., Roseiro, J. C., Martins, M. L. L., and Alves, L. (2016). "Sugarcane bagasse delignification with potassium hydroxide for enhanced enzymatic hydrolysis," RSC Advances 6(2), 1042-1052. DOI: 10.1039/C5RA14908H

Poursat, A. (2015). L'analyse des Constituants Chimiques du bois au sein de Populations Génétiques de Peuplier noir pour Faire de la Sélection d'Individus pour des Besoins de Production Énergétique [Analysis of Chemical Constituents of Wood in Genetic Populations of Black Poplar to Select Individuals for Energy Production Needs], Master's Thesis, Institut Universitaire de Technologie d'Orléans, Orléans, France.

Premkumari, Veerangouda, M., Palled, V., Anantachar, M., Hiregoudar, S., Naik, N. M., and Beladadhi, R. V. (2019). "Effect of potassium hydroxide (KOH) pretreatment on solids recovery, delignification and total sugars of cotton stalk," International Journal of Current Microbiology and Applied Sciences 8(02), 2457-2467. DOI:

10.20546/ijcmas.2019.802.286

Qi, B., Chen, X., Shen, F., Su, Y., and Wan, Y. (2009). “Optimization of enzymatic hydrolysis of wheat straw pretreated by alkaline peroxide using response surface methodology," Industrial \& Engineering Chemistry Research 48(15), 7346-7353. DOI: $10.1021 /$ ie8016863

Rachmawaty, Halifah, P., Hartati, Maulana, Z., and Salleh, M. (2019). “Optimization of chitinase production by Trichoderma virens in solid state fermentation using response surface methodology," Materials Science Forum 967, 132-142. DOI:

10.4028/www.scientific.net/MSF.967.132

Rais, F., Kamoun, A., Chaabouni, M., Claeys-Bruno, M., Luu, R. P. T., and Sergent, M. (2011). "Etude par plans d'expériences de la robustesse d'un procede de preparation de sulfate-amide des acides gras de l'huile de grignons d'olives [Study by experimental designs of the robustness of a process for preparing sulphate-amide of fatty acids from olive-pomace oil]," Journal de la Société Chimique de Tunisie 13, 
191-202.

Rambat, R., Aprilita, N. H., and Rusdiarso, B. (2015). “Aplikasi limbah kulit buah kakao sebagai media fermentasi asam laktat untuk bahan baku bioplastik [Application of cocoa pod husk waste as a medium for lactic acid fermentation for raw materials of bioplastics]," Jurnal Kimia dan Kemasan 37(2), 111-122. DOI: 10.24817/jkk.v37i2.1820

Samah, O. A., Sias, S., Hua, Y. G., and Hussin, N. N. (2011). "Production of ethanol from cocoa pod hydrolysate," ITB Journal of Science 43A(2), 87-94. DOI: 10.5614/itbj.sci.2011.43.2.2

Sandesh, K., Shishir, R. K., and Rao, C. V. (2020). "Optimization and comparison of induction heating and LPG assisted acid pretreatment of cocoa pod for ABE fermentation," Fuel 262, 1-9. DOI: 10.1016/j.fuel.2019.116499

Segal, L., Creely, J. J., Martin Jr., A. E., and Conrad, C. M. (1959). “An empirical method for estimating the degree of crystallinity of native cellulose using the X-ray diffractometer," Textile Research Journal 29(10), 786-794. DOI: 10.1177/004051755902901003

Sharma, R., Palled, V., Sharma-Shivappa, R. R., and Osborne, J. (2013). "Potential of potassium hydroxide pretreatment of switchgrass for fermentable sugar production," Applied Biochemistry and Biotechnology 169(3), 761-772. DOI: 10.1007/s12010012-0009-x

Sharmada, N., Punja, A., Shetty, S. S., Shet, V. B., Goveas, L. C., and Rao, C. V. (2016). "Optimization of pre-treatment of de-oiled oil seed cake for release of reducing sugars by response surface methodology," Bioethanol, De Gruyter, 1(open issue). DOI: 10.1515/bioeth-2016-0006

Shet, V. B., Nisha, Bhat, M., Manasa, Mascarenhas, L. N. S., Goveas, L. C., Rao, C. V., and Ujwal, P. (2016). "Optimization of $\mathrm{Na}_{2} \mathrm{CO}_{3}$ pre-treatment by RSM approach for releasing reducing sugars from cocoa pod shells," in: Biotechnology and Biochemical Engineering, P. B. D., S. N. Gummadi, and P. V. Vadlani (ed.), Springer Singapore, Singapore.

Shet, V. B., Sanil, N., Bhat, M., Naik, M., Mascarenhas, L. N., Goveas, L. C., Rao, C. V., Ujwal, P., Sandesh, K., and Aparna, A. (2018). "Acid hydrolysis optimization of cocoa pod shell using response surface methodology approach toward ethanol production," Agriculture and Natural Resources 52(6), 581-587. DOI: 10.1016/j.anres.2018.11.022

Sivamani, S., and Baskar, R. (2014). "Optimization of bioethanol production from cassava peel using statistical experimental design," Environmental Progress \& Sustainable Energy, 34(2), 567-574. DOI: 10.1002/ep.11984

Sluiter, A., Hames, B., Ruiz, R., Scarlata, C., Sluiter, J., Templeton, D., and Crocker, D. (2012). Determination of Structural Carbohydrates and Lignin in Biomass (NREL/TP-510-42618), National Renewable Energy Laboratory, Golden, CO.

Souza, L. d. S. S., Pereira, A. M., Farias, M. A. d. S., Oliveira, R. L. e., Duvoisin Jr., S., and Quaresma, J. N. N. (2020). "Valorization of andiroba (Carapa guianensis Aubl.) residues through optimization of alkaline pretreatment to obtain fermentable sugars," BioResources 15(1), 894-909. DOI: 10.15376/biores.15.1.894-909

Statista (2019). "Fèves de cacao: Production mondiale par pays 2016-2019 [Cocoa beans: world production by country 2016-2019]," (https://fr.statista.com/statistiques/565101/production-mondiale-feves-cacao-volumepar-pays/), accessed 11 April 2020. 
Thamsee, T., Choojit, S., Cheirsilp, B., Yamseangsung, R., Ruengpeerakul, T., and Sangwichien, C. (2019). "Combination of superheated steam explosion and alkaline autoclaving pretreatment for improvement of enzymatic digestibility of the oil palm tree residues as alternative sugar sources," Waste and Biomass Valorization 10(10), 3009-3023. DOI: 10.1007/s12649-018-0292-z

Titiloye, J. O., Bakar, M. S. A., and Odetoye, T. E. (2013). "Thermochemical characterisation of agricultural wastes from West Africa," Industrial Crops and Products 47, 199-203. DOI: 10.1016/j.indcrop.2013.03.011

Utekar, P. G., Kininge, M. M., and Gogate, P. R. (2021). "Intensification of delignification and enzymatic hydrolysis of orange peel waste using ultrasound for enhanced fermentable sugar production," Chemical Engineering and Processing Process Intensification 168, 108556. DOI: 10.1016/j.cep.2021.108556

Ward-Doria, M., Arzuaga-Garrido, J., Ojeda, K. A., and Sánchez, E. (2016). "Production of biogas from acid and alkaline pretreated cocoa pod husk (Theobroma cacao L.)," International Journal of ChemTech Research 9(11), 252-260.

Wasli, A. S., Salleh, M., Abd-Aziz, S., Hassan, O., and Mahadi, N. M. (2009). "Medium optimization for chitinase production from Trichoderma virens using central composite design," Biotechnology and Bioprocess Engineering 14(6), 781-787. DOI: $10.1007 / \mathrm{s} 12257-008-0127-\mathrm{z}$

Woiciechowski, A. L., Neto, C. J. D., Vandenberghe, L. P. d. S., Neto, D. P. d. C., Sydney, A. C. N., Letti, L. A. J., Karp, S. G., Torres, L. A. Z., and Soccol, C. R. (2020). "Lignocellulosic biomass: Acid and alkaline pretreatments and their effects on biomass recalcitrance - conventional processing and recent advances," Bioresource Technology 304, 1-9. DOI: 10.1016/j.biortech.2020.122848

Xie, X., Feng, X., Chi, S., Zhang, Y., Yu, G., Liu, C., Li, Z., Li, B., and Peng, H. (2018). "A sustainable and effective potassium hydroxide pretreatment of wheat straw for the production of fermentable sugars," Bioresource Technology Reports 3, 169-176. DOI: 10.1016/j.biteb.2018.07.014

$\mathrm{Xu}$, J., and Cheng, J. J. (2011). "Pretreatment of switchgrass for sugar production with the combination of sodium hydroxide and lime," Bioresource Technology 102(4), 3861-3868. DOI: 10.1016/j.biortech.2010.12.038

Article submitted: August 1, 2021; Peer review completed: October 9, 2021; Revised version received and accepted: November 10, 2021; Published: December 9, 2021.

DOI: $10.15376 /$ biores.17.1.826-848 